\title{
Best proximity points for generalized proximal $C$-contraction mappings in metric spaces with partial orders
}

\author{
Chirasak Mongkolkeha', Yeol Je Cho ${ }^{2^{*}}$ and Poom Kumam ${ }^{1 *}$
}

\footnotetext{
"Correspondence: yjcho@gnu.ac.kr; poom.kum@kmutt.ac.th 'Department of Mathematics, Faculty of Science, King Mongkut's University of Technology Thonburi (KMUTT), Bangmod, Thrungkru, Bangkok, 10140, Thailand ${ }^{2}$ Department of Mathematics Education and the RINS, Gyeongsang National University, Chinju, 660-701, Korea
}

\begin{abstract}
In this paper we extend the notion of weakly C-contraction mappings to the case of non-self mappings and establish the best proximity point theorems for this class. Our results generalize the result due to Harjani et al. (Comput. Math. Appl. 61:790-796, 2011) and some other authors.
\end{abstract}

\section{Introduction and preliminaries}

In 1922, Banach proved that every contractive mapping in a complete metric space has a unique fixed point, which is called Banach's fixed point theorem or Banach's contraction principle. Since Banach's fixed point theorem, many authors have extended, improved and generalized this theorem in several ways and, further, some applications of Banach's fixed point theorem can be found in [1-6] and many others.

In 1972, Chatterjea [7] introduced the following definition.

Definition 1.1 Let $(X, d)$ be a metric space. A mapping $T: X \rightarrow X$ is called a $C$-contraction if there exists $\alpha \in\left(0, \frac{1}{2}\right)$ such that, for all $x, y \in X$,

$$
d(T x, T y) \leq \alpha(d(x, T y)+d(y, T x))
$$

In 2009, Choudhury [8] introduced a generalization of $C$-contraction given by the following definition.

Definition 1.2 Let $(X, d)$ be a metric space. A mapping $T: X \rightarrow X$ is called a weakly $C$-contraction if, for all $x, y \in X$,

$$
d(T x, T y) \leq \frac{1}{2}[d(x, T y)+d(y, T x)]-\psi(d(x, T y), d(y, T x))
$$

where $\psi:[0, \infty)^{2} \rightarrow[0, \infty)$ is a continuous and nondecreasing function such that $\psi(x, y)=0$ if and only if $x=y=0$.

In 2011, Harjani et al. [9] presented some fixed point results for weakly $C$-contraction mappings in a complete metric space endowed with a partial order as follows.

(C) 2013 Mongkolkeha et al.; licensee Springer. This is an Open Access article distributed under the terms of the Creative Commons Attribution License (http://creativecommons.org/licenses/by/2.0), which permits unrestricted use, distribution, and reproduction in any medium, provided the original work is properly cited. 
Theorem 1.3 Let $(X, \preceq)$ be a partially ordered set and suppose that there exists a metric $d$ in $X$ such that $(X, d)$ is a complete metric space. Let $T: X \rightarrow X$ be a continuous and nondecreasing mapping such that

$$
d(T x, T y) \leq \frac{1}{2}[d(x, T y)+d(y, T x)]-\psi(d(x, T y), d(y, T x))
$$

for $x \preceq y$, where $\psi:[0, \infty)^{2} \rightarrow[0, \infty)$ is a continuous and nondecreasing function such that $\psi(x, y)=0$ if and only if $x=y=0$. If there exists $x_{0} \in X$ with $x_{0} \preceq T x_{0}$, then $T$ has a fixed point.

On the other hand, most of the results on Banach's fixed point theorem dilate upon the existence of a fixed point for self-mappings. Nevertheless, if $T$ is a non-self mapping, then it is probable that the equation $T x=x$ has no solution, in which case best approximation theorems explore the existence of an approximate solution, whereas best proximity point theorems analyze the existence of an approximate solution that is optimal.

A classical best approximation theorem was introduced by Fan [10], that is, if $A$ is a nonempty compact convex subset of a Hausdorff locally convex topological vector space $B$ and $T: A \rightarrow B$ is a continuous mapping, then there exists an element $x \in A$ such that $d(x, T x)=d(T x, A)$. Afterward, several authors including Prolla [11], Reich [12], Sehgal and Singh $[13,14]$ have derived the extensions of Fan's theorem in many directions. Other works on the existence of a best proximity point for some contractions can be seen in [1519]. In 2005, Eldred, Kirk and Veeramani [20] obtained best proximity point theorems for relatively nonexpansive mappings, and some authors have proved best proximity point theorems for several types of contractions (see, for example, [21-26]).

Let $X$ be a nonempty set such that $(X, \preceq)$ is a partially ordered set and let $(X, d)$ be a complete metric space. Let $A$ and $B$ be nonempty subsets of a metric space $(X, d)$. Now, we recall the following notions:

$$
\begin{aligned}
& d(A, B):=\inf \{d(x, y): x \in A \text { and } y \in B\}, \\
& A_{0}:=\{x \in A: d(x, y)=d(A, B) \text { for some } y \in B\}, \\
& B_{0}:=\{y \in B: d(x, y)=d(A, B) \text { for some } x \in A\} .
\end{aligned}
$$

If $A \cap B \neq \emptyset$, then $A_{0}$ and $B_{0}$ are nonempty. Further, it is interesting to notice that $A_{0}$ and $B_{0}$ are contained in the boundaries of $A$ and $B$, respectively, provided $A$ and $B$ are closed subsets of a normed linear space such that $d(A, B)>0$ (see [27]).

Definition 1.4 A mapping $T: A \rightarrow B$ is said to be increasing if

$$
x \preceq y \quad \Longrightarrow \quad S x \preceq S y
$$

for all $x, y \in A$. 
Definition 1.5 [28] A mapping $T: A \rightarrow B$ is said to be proximally order-preserving if and only if it satisfies the condition that

$$
\left.\begin{array}{l}
x \preceq y \\
d(u, T x)=d(A, B) \\
d(v, T y)=d(A, B)
\end{array}\right\} \Rightarrow u \preceq v
$$

for all $u, v, x, y \in A$.

It is easy to observe that for a self-mapping, the notion of a proximally order-preserving mapping reduces to that of an increasing mapping.

Definition 1.6 A point $x \in A$ is called a best proximity point of the mapping $T: A \rightarrow B$ if

$$
d(x, T x)=d(A, B) .
$$

In view of the fact that $d(x, T x) \geq d(A, B)$ for all $x$ in $A$, it can be observed that the global minimum of the mapping $x \mapsto d(x, T x)$ is attained from a best proximity point. Moreover, it is easy to see that the best proximity point reduces to a fixed point if the underlying mapping $T$ is a self-mapping.

In this paper, we introduce a new class of proximal contractions, which extends the class of weakly $C$-contractive mappings to the class of non-self mappings, and also give some examples to illustrate our main results. Our results extend and generalize the corresponding results given by Harjani et al. [9] and some authors in the literature.

\section{Main results}

In this section, we first introduce the notion of a generalized proximal $C$-contraction mapping and establish the best proximity point theorems.

Definition 2.1 A mapping $T: A \rightarrow B$ is said to be a generalized proximal $C$-contraction if, for all $u, v, x, y \in A$, it satisfies

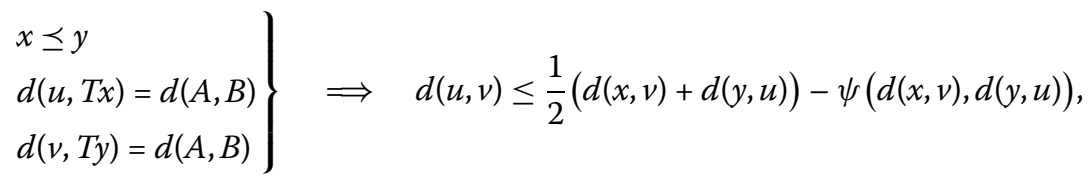

where $\psi:[0, \infty)^{2} \rightarrow[0, \infty)$ is a continuous and nondecreasing function such that $\psi(x, y)=0$ if and only if $x=y=0$.

For a self-mapping, it is easy to see that equation (2.1) reduces to (1.1).

Theorem 2.2 Let $X$ be a nonempty set such that $(X, \preceq)$ is a partially ordered set and let $(X, d)$ be a complete metric space. Let $A$ and $B$ be nonempty closed subsets of $X$ such that $A_{0}$ and $B_{0}$ are nonempty. Let $T: A \rightarrow B$ satisfy the following conditions:

(a) $T$ is a continuous, proximally order-preserving and generalized proximal $C$-contraction such that $T\left(A_{0}\right) \subseteq B_{0}$; 
(b) there exist elements $x_{0}$ and $x_{1}$ in $A_{0}$ such that $x_{0} \preceq x_{1}$ and

$$
d\left(x_{1}, T x_{0}\right)=d(A, B) .
$$

Then there exists a point $x \in A$ such that

$$
d(x, T x)=d(A, B)
$$

Moreover, for any fixed $x_{0} \in A_{0}$, the sequence $\left\{x_{n}\right\}$ defined by

$$
d\left(x_{n+1}, T x_{n}\right)=d(A, B)
$$

converges to the point $x$.

Proof By the hypothesis (b), there exist $x_{0}, x_{1} \in A_{0}$ such that $x_{0} \preceq x_{1}$ and

$$
d\left(x_{1}, T x_{0}\right)=d(A, B) .
$$

Since $T\left(A_{0}\right) \subseteq B_{0}$, there exists a point $x_{2} \in A_{0}$ such that

$$
d\left(x_{2}, T x_{1}\right)=d(A, B) .
$$

By the proximally order-preserving property of $T$, we get $x_{1} \preceq x_{2}$. Continuing this process, we can find a sequence $\left\{x_{n}\right\}$ in $A_{0}$ such that $x_{n-1} \preceq x_{n}$ and

$$
d\left(x_{n}, T x_{n-1}\right)=d(A, B) .
$$

Having found the point $x_{n}$, one can choose a point $x_{n+1} \in A_{0}$ such that $x_{n} \preceq x_{n+1}$ and

$$
d\left(x_{n+1}, T x_{n}\right)=d(A, B) .
$$

Since $T$ is a generalized proximal $C$-contraction, for each $n \in \mathbb{N}$, we have

$$
\begin{aligned}
d\left(x_{n}, x_{n+1}\right) & \leq \frac{1}{2}\left(d\left(x_{n-1}, x_{n+1}\right)+d\left(x_{n}, x_{n}\right)\right)-\psi\left(d\left(x_{n-1}, x_{n+1}\right), d\left(x_{n}, x_{n}\right)\right) \\
& =\frac{1}{2} d\left(x_{n-1}, x_{n+1}\right)-\psi\left(d\left(x_{n-1}, x_{n+1}\right), 0\right) \\
& \leq \frac{1}{2} d\left(x_{n-1}, x_{n+1}\right) \\
& \leq \frac{1}{2}\left(d\left(x_{n-1}, x_{n}\right)+d\left(x_{n}, x_{n+1}\right)\right)
\end{aligned}
$$

and so it follows that $d\left(x_{n}, x_{n+1}\right) \leq d\left(x_{n-1}, x_{n}\right)$, that is, the sequence $\left\{d\left(x_{n+1}, x_{n}\right)\right\}$ is nonincreasing and bounded below. Then there exists $r \geq 0$ such that

$$
\lim _{n \rightarrow \infty} d\left(x_{n+1}, x_{n}\right)=r
$$


Taking $n \rightarrow \infty$ in (2.3), we have

$$
r \leq \lim _{n \rightarrow \infty} \frac{1}{2} d\left(x_{n-1}, x_{n+1}\right) \leq \frac{1}{2}(r+r)=r
$$

and so

$$
\lim _{n \rightarrow \infty} d\left(x_{n-1}, x_{n+1}\right)=2 r
$$

Again, taking $n \rightarrow \infty$ in (2.3) and using (2.4), (2.5) and the continuity of $\psi$, we get

$$
r \leq \frac{1}{2}(2 r)=r-\psi(2 r, 0) \leq r
$$

and hence $\psi(2 r, 0)=0$. So, by the property of $\psi$, we have $r=0$, which implies that

$$
\lim _{n \rightarrow \infty} d\left(x_{n+1}, x_{n}\right)=0
$$

Next, we prove that $\left\{x_{n}\right\}$ is a Cauchy sequence. Suppose that $\left\{x_{n}\right\}$ is not a Cauchy sequence. Then there exist $\varepsilon>0$ and subsequences $\left\{x_{m_{k}}\right\},\left\{x_{n_{k}}\right\}$ of $\left\{x_{n}\right\}$ such that $n_{k}>m_{k} \geq k$ with

$$
r_{k}:=d\left(x_{m_{k}}, x_{n_{k}}\right) \geq \varepsilon, \quad d\left(x_{m_{k}}, x_{n_{k}-1}\right)<\varepsilon
$$

for each $k \in\{1,2,3, \ldots\}$. For each $n \geq 1$, let $\alpha_{n}:=d\left(x_{n+1}, x_{n}\right)$. So, we have

$$
\begin{aligned}
\varepsilon & \leq r_{k} \leq d\left(x_{m_{k}}, x_{n_{k}-1}\right)+d\left(x_{n_{k}-1}, x_{n_{k}}\right) \\
& <\varepsilon+\alpha_{n_{k}-1} .
\end{aligned}
$$

It follows from (2.6) that

$$
\lim _{k \rightarrow \infty} r_{k}=\varepsilon
$$

Notice also that

$$
\begin{aligned}
r_{k} & =d\left(x_{n_{k}}, x_{m_{k}}\right) \leq d\left(x_{n_{k}}, x_{m_{k}+1}\right)+d\left(x_{m_{k}+1}, x_{m_{k}}\right) \\
& =d\left(x_{n_{k}}, x_{m_{k}+1}\right)+\alpha_{m_{k}} \\
& \leq d\left(x_{n_{k}}, x_{m_{k}}\right)+d\left(x_{m_{k}}, x_{m_{k}+1}\right)+\alpha_{m_{k}} \\
& =r_{k}+\alpha_{m_{k}}+\alpha_{m_{k}} .
\end{aligned}
$$

Taking $k \rightarrow \infty$ in (2.9), by (2.6) and (2.8), we conclude that

$$
\lim _{k \rightarrow \infty} d\left(x_{n_{k}}, x_{m_{k}+1}\right)=\varepsilon
$$

Similarly, we can show that

$$
\lim _{k \rightarrow \infty} d\left(x_{m_{k}}, x_{n_{k}+1}\right)=\varepsilon .
$$


On the other hand, by the construction of $\left\{x_{n}\right\}$, we may assume that $x_{m_{k}} \preceq x_{n_{k}}$ such that

$$
d\left(x_{n_{k}+1}, T x_{n_{k}}\right)=d(A, B)
$$

and

$$
d\left(x_{m_{k}+1}, T x_{m_{k}}\right)=d(A, B) .
$$

By the triangle inequality, (2.12), (2.13) and the generalized proximal $C$-contraction of $T$, we have

$$
\begin{aligned}
\varepsilon \leq & r_{k} \leq d\left(x_{m_{k}}, x_{m_{k}+1}\right)+d\left(x_{n_{k}+1}, x_{n_{k}}\right)+d\left(x_{m_{k}+1}, x_{n_{k}+1}\right) \\
= & \alpha_{m_{k}}+\alpha_{n_{k}}+d\left(x_{m_{k}+1}, x_{n_{k}+1}\right) \\
\leq & \alpha_{m_{k}}+\alpha_{n_{k}}+\frac{1}{2}\left[d\left(x_{n_{k}}, x_{m_{k}+1}\right)+d\left(x_{m_{k}}, x_{n_{k}+1}\right)\right] \\
& -\psi\left(d\left(x_{n_{k}}, x_{m_{k}+1}\right), d\left(x_{m_{k}}, x_{n_{k}+1}\right)\right) .
\end{aligned}
$$

Taking $k \rightarrow \infty$ in the above inequality, by (2.6), (2.10), (2.11) and the continuity of $\psi$, we get

$$
\varepsilon \leq \frac{1}{2}(\varepsilon+\varepsilon)-\psi(\varepsilon, \varepsilon) \leq \varepsilon
$$

Therefore, $\psi(\varepsilon, \varepsilon)=0$. By the property of $\psi$, we have that $\varepsilon=0$, which is a contradiction. Thus $\left\{x_{n}\right\}$ is a Cauchy sequence. Since $A$ is a closed subset of the complete metric space $X$, there exists $x \in A$ such that

$$
\lim _{n \rightarrow \infty} x_{n}=x
$$

Letting $n \rightarrow \infty$ in (2.2), by (2.14) and the continuity of $T$, it follows that

$$
d(x, T x)=d(A, B) .
$$

Corollary 2.3 Let $X$ be a nonempty set such that $(X, \preceq)$ is a partially ordered set and let $(X, d)$ be a complete metric space. Let $A$ and $B$ be nonempty closed subsets of $X$ such that $A_{0}$ and $B_{0}$ are nonempty. Let $T: A \rightarrow B$ satisfy the following conditions:

(a) $T$ is continuous, increasing such that $T\left(A_{0}\right) \subseteq B_{0}$ and

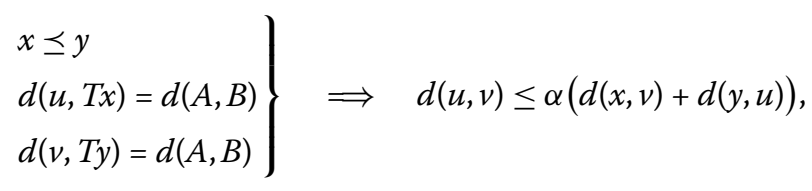

where $\alpha \in\left(0, \frac{1}{2}\right)$;

(b) there exist $x_{0}, x_{1} \in A_{0}$ such that $x_{0} \preceq x_{1}$ and

$$
d\left(x_{1}, T x_{0}\right)=d(A, B)
$$


Then there exists a point $x \in A$ such that

$$
d(x, T x)=d(A, B)
$$

Moreover, for any fixed $x_{0} \in A_{0}$, the sequence $\left\{x_{n}\right\}$ defined by

$$
d\left(x_{n+1}, T x_{n}\right)=d(A, B)
$$

converges to the point $x$.

Proof Let $\alpha \in\left(0, \frac{1}{2}\right)$ and the function $\psi$ in Theorem 2.2 be defined by

$$
\psi(a, b)=\left(\frac{1}{2}-\alpha\right)(a+b)
$$

Obviously, it follows that $\psi(a, b)=0$ if and only if $a=b=0$ and (2.1) become (2.15). Hence we obtain Corollary 2.3.

For a self-mapping, the condition (b) implies that $x_{0} \preceq T x_{0}$ and so Theorem 2.2 includes the results of Harjani et al. [9] as follows.

Corollary 2.4 [9] Let $X$ be a nonempty set such that $(X, \preceq)$ is a partially ordered set and let $(X, d)$ be a complete metric space. Let $T: X \rightarrow X$ be a continuous and nondecreasing mapping such that, for all $x, y \in X$,

$$
d(T x, T y) \leq \frac{1}{2}[d(x, T y)+d(y, T x)]-\psi(d(x, T y), d(y, T x))
$$

for $x \preceq y$, where $\psi:[0, \infty)^{2} \rightarrow[0, \infty)$ is a continuous and nondecreasing function such that $\psi(x, y)=0$ if and only if $x=y=0$. If there exists $x_{0} \in X$ with $x_{0} \preceq T x_{0}$, then $T$ has a fixed point.

Now, we give an example to illustrate Theorem 2.2.

Example 2.5 Consider the complete metric space $\mathbb{R}^{2}$ with an Euclidean metric. Let

$$
A=\{(x, 0): x \in \mathbb{R}\}, \quad B=\{(0, y): y \in \mathbb{R}, y \geq 1\} .
$$

Then $d(A, B)=1, A_{0}=\{(0,0)\}$ and $B_{0}=\{(0,1)\}$. Define a mapping $T: A \rightarrow B$ as follows:

$$
T((x, 0))=(0,1+|x|)
$$

for all $(x, 0) \in A$. Clearly, $T$ is continuous and $T\left(A_{0}\right) \subseteq B_{0}$. If $x_{1} \preceq x_{2}$ and

$$
d\left(u_{1}, T x_{1}\right)=d(A, B)=1, \quad d\left(u_{2}, T x_{2}\right)=d(A, B)=1
$$

for some $u_{1}, u_{2}, x_{1}, x_{2} \in A$, then we have

$$
u_{1}=u_{1}=(0,0), \quad x_{1}=x_{2}=(0,0) .
$$


Therefore, $T$ is a generalized proximal $C$-contraction with $\psi:[0, \infty)^{2} \rightarrow[0, \infty)$ defined by

$$
\psi(a, b)=\frac{1}{4}(a+b)
$$

Further, observe that $(0,0) \in A$ such that

$$
d((0,0), T(0,0))=d(A, B)=1
$$

In Theorem 2.6, we do not need the condition that $T$ is continuous. Now, we improve the condition in Theorem 2.2 to prove the new best proximity point theorem as follows.

Theorem 2.6 Let $X$ be a nonempty set such that $(X, \preceq)$ is a partially ordered set and let $(X, d)$ be a complete metric space. Let $A$ and $B$ be nonempty closed subsets of $X$ such that $A_{0}$ and $B_{0}$ are nonempty. Let $T: A \rightarrow B$ satisfy the following conditions:

(a) $T$ is a proximally order-preserving and generalized proximal $C$-contraction such that $T\left(A_{0}\right) \subseteq B_{0}$

(b) there exist elements $x_{0}, x_{1} \in A_{0}$ such that $x_{0} \preceq x_{1}$ and

$$
d\left(x_{1}, T x_{0}\right)=d(A, B)
$$

(c) if $\left\{x_{n}\right\}$ is an increasing sequence in $A$ converging to $x$, then $x_{n} \preceq x$ for all $n \in \mathbb{N}$.

Then there exists a point $x \in A$ such that

$$
d(x, T x)=d(A, B) .
$$

Proof As in the proof of Theorem 2.2, we have

$$
d\left(x_{n+1}, T x_{n}\right)=d(A, B)
$$

for all $n \geq 0$. Moreover, $\left\{x_{n}\right\}$ is a Cauchy sequence and converges to some point $x \in A$. Observe that for each $n \in \mathbb{N}$,

$$
\begin{aligned}
d(A, B) & =d\left(x_{n+1}, T x_{n}\right) \leq d\left(x_{n+1}, x\right)+d\left(x, T x_{n}\right) \\
& \leq d\left(x, x_{n+1}\right)+d\left(x, x_{n+1}\right)+d\left(x_{n+1}, T x_{n}\right) \\
& \leq d\left(x, x_{n+1}\right)+d\left(x, x_{n+1}\right)+d(A, B) .
\end{aligned}
$$

Taking $n \rightarrow \infty$ in the above inequality, we obtain $\lim _{n \rightarrow \infty} d\left(x, T x_{n}\right)=d(A, B)$ and hence $x \in A_{0}$. Since $T\left(A_{0}\right) \subseteq B_{0}$, there exists $v \in A$ such that

$$
d(v, T x)=d(A, B)
$$

Next, we prove that $x=v$. By the condition (c), we have $x_{n} \preceq x$ for all $n \in \mathbb{N}$. Using (2.16), (2.17) and the generalized proximal $C$-contraction of $T$, we have

$$
d\left(x_{n+1}, v\right) \leq \frac{1}{2}\left[d\left(x_{n}, v\right)+d\left(x, x_{n+1}\right)\right]-\psi\left(d\left(x_{n}, v\right), d\left(x, x_{n+1}\right)\right) .
$$


Letting $n \rightarrow \infty$ in (2.18), we get

$$
d(x, v) \leq \frac{1}{2} d(x, v)-\psi(d(x, v), 0)
$$

which implies that $d(x, v)=0$, that is, $x=v$. If we replace $v$ by $x$ in (2.17), we have

$$
d(x, T x)=d(A, B) .
$$

Corollary 2.7 Let $X$ be a nonempty set such that $(X, \preceq)$ is a partially ordered set and let $(X, d)$ be a complete metric space. Let $A$ and $B$ be nonempty closed subsets of $X$ such that $A_{0}$ and $B_{0}$ are nonempty. Let $T: A \rightarrow B$ satisfy the following conditions:

(a) $T$ is an increasing mapping such that $T\left(A_{0}\right) \subseteq B_{0}$ and

$$
\left.\begin{array}{l}
x \leq y \\
d(u, T x)=d(A, B) \\
d(v, T y)=d(A, B)
\end{array}\right\} \Rightarrow d(u, v) \leq \alpha(d(x, v)+d(y, u)),
$$

where $\alpha \in\left(0, \frac{1}{2}\right)$;

(b) there exist $x_{0}, x_{1} \in A_{0}$ such that $x_{0} \preceq x_{1}$ and

$$
d\left(x_{1}, T x_{0}\right)=d(A, B)
$$

(c) if $\left\{x_{n}\right\}$ is an increasing sequence in $A$ converging to a point $x \in X$, then $x_{n} \preceq x$ for all $n \in \mathbb{N}$.

Then there exists a point $x \in A$ such that

$$
d(x, T x)=d(A, B) .
$$

Corollary 2.8 [9] Let $X$ be a nonempty set such that $(X, \preceq)$ is a partially ordered set and let $(X, d)$ be a complete metric space. Assume that if $\left\{x_{n}\right\} \subseteq X$ is a nondecreasing sequence such that $x_{n} \rightarrow x$ in $X$, then $x_{n} \preceq x$ for all $n \in \mathbb{N}$. Let $T: X \rightarrow X$ be a nondecreasing mapping such that

$$
d(T x, T y) \leq \frac{1}{2}[d(x, T y)+d(y, T x)]-\psi(d(x, T y), d(y, T x))
$$

for $x \preceq y$, where $\psi:[0, \infty)^{2} \rightarrow[0, \infty)$ is a continuous and nondecreasing function such that $\psi(x, y)=0$ if and only if $x=y=0$. If there exists $x_{0} \in X$ with $x_{0} \preceq T x_{0}$, then $T$ has a fixed point.

Now, we recall the condition defined by Nieto and Rodríguez-López [3] for the uniqueness of the best proximity point in Theorems 2.2 and 2.6.

For $x, y \in X$, there exists $z \in X$ which is comparable to $x$ and $y$.

Theorem 2.9 Let $X$ be a nonempty set such that $(X, \preceq)$ is a partially ordered set and let $(X, d)$ be a complete metric space. Let $A$ and $B$ be nonempty closed subsets of $X$ and let $A_{0}$ 
and $B_{0}$ be nonempty such that $A_{0}$ satisfies the condition (2.20). Let $T: A \rightarrow B$ satisfy the following conditions:

(a) $T$ is a continuous, proximally order-preserving and generalized proximal $C$-contraction such that $T\left(A_{0}\right) \subseteq B_{0}$;

(b) there exist elements $x_{0}$ and $x_{1}$ in $A_{0}$ such that $x_{0} \preceq x_{1}$ and

$$
d\left(x_{1}, T x_{0}\right)=d(A, B) .
$$

Then there exists a unique point $x \in A$ such that

$$
d(x, T x)=d(A, B) .
$$

Proof We will only prove the uniqueness of the point $x \in A$ such that $d(x, T x)=d(A, B)$. Suppose that there exist $x$ and $x^{*}$ in $A$ which are best proximity points, that is,

$$
d(x, T x)=d(A, B) \quad \text { and } \quad d\left(x^{*}, T x^{*}\right)=d(A, B) .
$$

Case I: $x$ is comparable to $x^{*}$, that is, $x \preceq x^{*}$ (or $x^{*} \preceq x$ ). By the generalized proximal $C$-contraction of $T$, we have

$$
d\left(x, x^{\prime \prime}\right) \leq \frac{1}{2}\left[d\left(x, x^{*}\right)+d\left(x^{\prime \prime}, x\right)\right]-\psi\left(d\left(x, x^{*}\right), d\left(x^{\prime \prime}, x\right)\right) \leq d\left(x^{*}, x\right),
$$

which implies that $\psi\left(d\left(x, x^{*}\right), d\left(x^{*}, x\right)\right)=0$. Using the property of $\psi$, we get $d\left(x^{*}, x\right)=0$ and hence $x=x^{*}$.

Case II: $x$ is not comparable to $x "$. Since $A_{0}$ satisfies the condition (2.20), then there exists $z \in A_{0}$ such that $z$ is comparable to $x$ and $x^{*}$, that is, $x \preceq z$ (or $z \preceq x$ ) and $x^{*} \preceq z$ (or $z \preceq x^{*}$ ). Suppose that $x \preceq z$ and $x^{\prime \prime} \preceq z$. Since $T\left(A_{0}\right) \subseteq B_{0}$, there exists a point $v_{0} \in A_{0}$ such that

$$
d\left(v_{0}, T z\right)=d(A, B) .
$$

By the proximally order-preserving property of $T$, we get $x \preceq v_{0}$ and $x^{*} \preceq v_{0}$. Since $T\left(A_{0}\right) \subseteq$ $B_{0}$, there exists a point $v_{1} \in A_{0}$ such that

$$
d\left(v_{1}, T v_{0}\right)=d(A, B) .
$$

Again, by the proximally order-preserving property of $T$, we get $x \preceq v_{1}$ and $x^{*} \preceq v_{1}$. One can proceed further in a similar fashion to find $v_{n}$ in $A_{0}$ with $v_{n+1} \in A_{0}$ such that

$$
d\left(v_{n+1}, T v_{n}\right)=d(A, B) .
$$

Hence $x \preceq v_{n}$ and $x^{*} \preceq v_{n}$ for all $n \in \mathbb{N}$. By the generalized proximal $C$-contraction of $T$, we have

$$
\begin{aligned}
& d\left(v_{n+1}, x\right) \leq \frac{1}{2}\left[d\left(v_{n}, x\right)+d\left(x, v_{n+1}\right)\right]-\psi\left(d\left(v_{n}, x\right), d\left(x, v_{n+1}\right)\right), \\
& d\left(v_{n+1}, x^{*}\right) \leq \frac{1}{2}\left[d\left(v_{n}, x^{*}\right)+d\left(x^{*}, v_{n+1}\right)\right]-\psi\left(d\left(v_{n}, x^{*}\right), d\left(x^{*}, v_{n+1}\right)\right) .
\end{aligned}
$$


It follows from (2.21), (2.22) and the property of $\psi$ that

$$
v_{n} \rightarrow x \text { and } v_{n} \rightarrow x^{*} \quad \text { as } n \rightarrow \infty .
$$

By the uniqueness of limit, we conclude that $x=x^{*}$. Other cases can we proved similarly and this completes the proof.

Theorem 2.10 Let $X$ be a nonempty set such that $(X, \preceq)$ is a partially ordered set and let $(X, d)$ be a complete metric space. Let $A$ and $B$ be nonempty closed subsets of $X$ and let $A_{0}$ and $B_{0}$ be nonempty such that $A_{0}$ satisfies the condition (2.20). Let $T: A \rightarrow B$ satisfy the following conditions:

(a) $T$ is a proximally order-preserving and generalized proximal $C$-contraction such that $T\left(A_{0}\right) \subseteq B_{0}$

(b) there exist elements $x_{0}, x_{1} \in A_{0}$ such that $x_{0} \preceq x_{1}$ and

$$
d\left(x_{1}, T x_{0}\right)=d(A, B)
$$

(c) if $\left\{x_{n}\right\}$ is an increasing sequence in $A$ converging to $x$, then $x_{n} \preceq x$ for all $n \in \mathbb{N}$.

Then there exists a unique point $x \in A$ such that

$$
d(x, T x)=d(A, B) .
$$

Proof For the proof, combine the proofs of Theorems 2.6 and 2.9.

\author{
Competing interests \\ The authors declare that they have no competing interests.
}

Authors' contributions

All authors contributed equally and significantly in writing this paper. All authors read and approved the final manuscript.

\title{
Acknowledgements
}

This research was partially finished at the Department of Mathematics Education, Gyeongsang National University, Republic of Korea. Mr. Chirasak Mongkolkeha was supported by the Thailand Research Fund through the Royal Golden Jubilee Program under Grant PHD/0029/2553 for the Ph.D. program at KMUTT, Thailand. Also, the second author was supported by the Basic Science Research Program through the National Research Foundation of Korea (NRF) funded by the Ministry of Education, Science, and Technology (NRF-2012-0008170). The third author was supported by the Commission on Higher Education, the Thailand Research Fund, and the King Mongkut's University of Technology Thonburi (KMUTT) (Grant No. MRG5580213).

Received: 28 October 2012 Accepted: 18 February 2013 Published: 6 March 2013

\section{References}

1. Agarwal, RP, EL-Gebeily, MA, O'regan, D: Generalized contractions in partially ordered metric spaces. Appl. Anal. 87, 109-116 (2008)

2. Cho, YJ: Fixed points for compatible mappings of type (A). Math. Jpn. 18, 497-508 (1993)

3. Nieto, JJ, Rodríguez-López, R: Contractive mapping theorems in partially ordered sets and applications to ordinary differential equations. Order 22, 223-239 (2005)

4. Pathak, HK, Cho, YJ, Kang, SM: Remarks on R-weakly commuting mappings and common fixed point theorems. Bull. Korean Math. Soc. 34, 247-257 (1997)

5. Sessa, S, Cho, YJ: Compatible mappings and a common fixed point theorem of Chang type. Publ. Math. (Debr.) 43, 289-296 (1993)

6. Sintunavarat, W, Cho, YJ, Kumam, P: Common fixed point theorems for c-distance in ordered cone metric spaces. Comput. Math. Appl. 62, 1969-1978 (2011)

7. Chatterjea, SK: Fixed point theorems. C. R. Acad. Bulgare Sci. 25, 727-730 (1972)

8. Choudhury, BS: Unique fixed point theorem for weak-contractive mappings. Kathmandu Univ. J. Sci. Eng. Technol. 5, 6-13 (2009) 
9. Harjani, J, López, B, Sadarangani, K: Fixed point theorems for weakly C-contractive mappings in ordered metric spaces. Comput. Math. Appl. 61, 790-796 (2011)

10. Fan, K: Extensions of two fixed point theorems of F.E. Browder. Math. Z. 112, 234-240 (1969)

11. Prolla, JB: Fixed point theorems for set valued mappings and existence of best approximations. Numer. Funct. Anal. Optim. 5, 449-455 (1982-1983)

12. Reich, S: Approximate selections, best approximations, fixed points and invariant sets. J. Math. Anal. Appl. 62, 104-113 (1978)

13. Sehgal, VM, Singh, SP: A generalization to multifunctions of Fan's best approximation theorem. Proc. Am. Math. Soc. 102, 534-537 (1988)

14. Sehgal, VM, Singh, SP: A theorem on best approximations. Numer. Funct. Anal. Optim. 10, 181-184 (1989)

15. Al-Thagafi, MA, Shahzad, N: Convergence and existence results for best proximity points. Nonlinear Anal. 70, 3665-3671 (2009)

16. Eldred, AA, Veeramani, P: Existence and convergence of best proximity points. J. Math. Anal. Appl. 323, 1001-1006 (2006)

17. Di Bari, C, Suzuki, T, Vetro, C: Best proximity points for cyclic Meir-Keeler contractions. Nonlinear Anal. 69, 3790-3794 (2008)

18. Karpagam, S, Agrawal, S: Best proximity point theorems for $p$-cyclic Meir-Keeler contractions. Fixed Point Theory Appl. 2009, Article ID 197308 (2009)

19. Mongkolkeha, C, Kumam, P: Some common best proximity points for proximity commuting mappings. Optim. Lett (2012, in press). doi:10.1007/s11590-012-0525-1

20. Eldred, AA, Kirk, WA, Veeramani, P: Proximal normal structure and relatively nonexpanisve mappings. Stud. Math. 171, 283-293 (2005)

21. Al-Thagafi, MA, Shahzad, N: Best proximity pairs and equilibrium pairs for Kakutani multimaps. Nonlinear Anal. 70, 1209-1216 (2009)

22. Mongkolkeha, C, Kumam, P: Best proximity point theorems for generalized cyclic contractions in ordered metric spaces. J. Optim. Theory Appl. 155, 215-226 (2012)

23. Kirk, WA, Reich, S, Veeramani, P: Proximinal retracts and best proximity pair theorems. Numer. Funct. Anal. Optim. 24, $851-862(2003)$

24. Wlodarczyk, K, Plebaniak, R, Banach, A: Best proximity points for cyclic and noncyclic set-valued relatively quasi-asymptotic contractions in uniform spaces. Nonlinear Anal. 70, 3332-3341 (2009)

25. Wlodarczyk, K, Plebaniak, R, Banach, A: Erratum to: 'Best proximity points for cyclic and noncyclic set-valued relatively quasi-asymptotic contractions in uniform spaces.' Nonlinear Anal. 71, 3583-3586 (2009)

26. Sintunavarat, W, Kumam, P: Coupled best proximity point theorem in metric spaces. Fixed Point Theory Appl. 2012 93 (2012). doi:10.1186/1687-1812-2012-93

27. Sadiq Basha, S, Veeramani, P: Best proximity pair theorems for multifunctions with open fibres. J. Approx. Theory 103, 119-129 (2000)

28. Sadiq Basha, S: Best proximity point theorems on partially ordered sets. Optim. Lett. (2012) doi:10.1007/s11590-012-0489-1

doi:10.1186/1029-242X-2013-94

Cite this article as: Mongkolkeha et al.: Best proximity points for generalized proximal C-contraction mappings in metric spaces with partial orders. Journal of Inequalities and Applications 2013 2013:94.

\section{Submit your manuscript to a SpringerOpen ${ }^{\circ}$ journal and benefit from:}

- Convenient online submission

- Rigorous peer review

- Immediate publication on acceptance

- Open access: articles freely available online

- High visibility within the field

- Retaining the copyright to your article 